\title{
Overview of control, integration and energy management of microgrids
}

\author{
Yunwei LI (ه), Farzam NEJABATKHAH
}

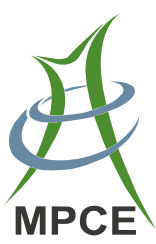

\begin{abstract}
Microgrids are being developed as a building block for future smart grid system. Key issues for the control and operation of microgrid include integration technologies and energy management schemes. This paper presents an overview of grid integration and energy management strategies of microgrids. It covers a review of power electronics interface topologies for different types of distributed generation (DG) units in a microgrid, a discussion of energy management strategies, as well as the DG interfacing converter control schemes. Considering the intermittent nature of many renewable energy based DG units, the ancillary services of DGs using the available interfacing converter rating are also discussed in the paper.
\end{abstract}

Keywords Distributed generation, Energy management schemes, Harmonic compensation, Interfacing converters, Microgrid, Power quality, Unbalance voltage

compensation

\section{Introduction}

In recent years, the rapid increase of distributed generation (DG) installation, especially those based on renewable energy sources, is expected to address the concerns on greenhouse gas emissions, energy sustainability, energy

CrossCheck date: 9 June 2014

Received: 22 May 2014 / Accepted: 10 July 2014/Published online: 19 August 2014

(C) The Author(s) 2014. This article is published with open access at Springerlink.com

Y. LI, F. NEJABATKHAH, Department of Electrical and

Computer Engineering, University of Alberta, Edmonton, AB,

Canada

(凹) e-mail: yunwei.li@ualberta.ca

F. NEJABATKHAH

e-mail: nejabatk@ualberta.ca security, etc. Among various kinds of renewable energy based DGs, wind and photovoltaic (PV) power generation are relatively mature and are the fastest growing DG technologies. Since mid-1990s, wind power installation has been growing by $25 \%$ per year. By 2011, China has the highest installed wind power capacity with more than 60 GW [1]. PV installation follows a similar trend, but with an even faster growth rate around $48 \%$ each year in recent years, making it the fastest growing energy technology in the world. As of 2011, PV installation has reached around $70 \mathrm{GW}$ with Germany as the leader [2]. In addition to renewable energy sources, alternative energy sources or micro sources such as fuel cells and microturbines have also been used increasingly in recent years for power generation. Fuel cells produce electrical power directly from chemical energy contained in a fuel, which can be hydrogen, natural gas, methanol, gasoline, etc. These power generations are inherently modular in nature, and their capacity can be added easily as loads grow. On the other hand, microturbines had been originally designed for aircrafts applications [3]. Modern microturbines using advanced components such as heat exchangers, power electronics, communications, and control systems are becoming more popular for DG applications [3].

A common feature of the renewable energy based or micro sources based DG systems is the power electronics interfaces that required to convert the energy sources output to the grid ready voltages [4]. These power electronics also provide enhanced flexibility for the DG operation and energy management. In order to better organize these DG systems, the concept of microgrid has been developed, which has higher capacity and more control flexibility compared to a single DG systems. A microgrid can operate in both grid-connected and stand-alone operation modes and benefit both utility and customers with better reliability and power quality. However, the operation and control of 


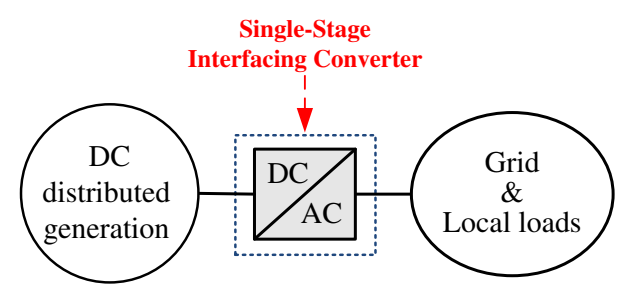

(a) single stage dc-ac interfacing converter

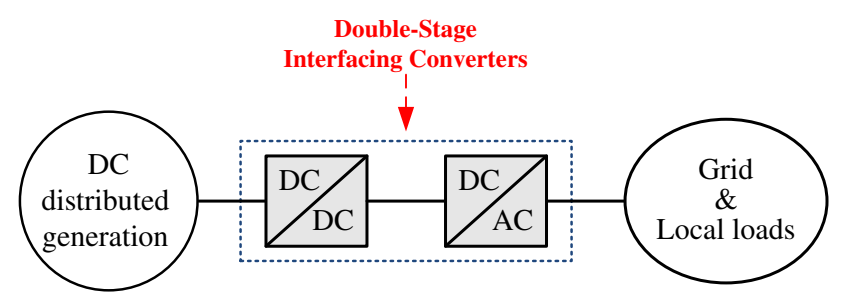

(b) double-stage dc-dc and dc-ac interfacing converters

Fig. 1 Power electronics interfaces for DGs with dc output powers

microgrid also present challenges in terms of DG-grid integration technologies, current/voltage control strategies and energy management schemes.

For proper operation of a microgrid, energy management strategies are important to regulate the output powers of each DG as well as the voltage and frequency of the microgrid systems [5-7]. Additionally, to achieve improved power quality in a microgrid, proper design and control of the DG interfacing converters to provide the ancillary services are important. This is particularly true when considering that most renewable energy based DG systems are not always operating at their rated power, and the available converter rating can be used to facilitate grid frequency and voltage regulation, harmonics control, unbalance voltage compensation, etc.

This paper presents an overview of grid integration technologies and energy management schemes of microgrids. First, different DG interfacing converter topologies are reviewed and their applications and development trend are discussed. Different types of energy management schemes including communication-based and communication-less strategies are then reviewed. In addition, the control schemes of DG interfacing converter are discussed. At last, ancillary services of DG systems and microgrids for grid support and power quality improvement are presented.

\section{Interfacing converter topologies}

Since the output of renewable energy sources and micro sources are mainly $\mathrm{dc}$ or non-utility-grade ac, power electronic converters are critical to interface the energy source to the grid in these DG systems. In the DG interfacing power electronic converters, the requirements related to the energy source characteristics, the energy storage system, the distribution system configuration, voltage levels, power quality, etc. need to be considered.

For DGs with dc output power such as PV and fuel cell, the interfacing converters can be classified as single-stage and double-stage configurations. These configurations are shown in Fig. 1. The double-stage topology is the traditional solution. In this topology, the first stage dc-dc converter is mainly used for two purposes: boost the dc link voltage and control DGs' output power with maximum power point tracking (in PV) or maximum efficiency operation (in fuel cell). The second stage dc-ac converter can work on dc bus voltage control mode, or output power/ current control mode depending on different control requirements. In such as system, electrical isolation is typically provided by high frequency transformer in the $\mathrm{dc}-\mathrm{dc}$ converters such as flyback or push-pull dc-dc converters with lower weight and size.

On the other hand, the single-stage topology is becoming more popular in recent years. It features higher efficiency with less power electronics converters and power conversion process. However its drawbacks include compromised control flexibility and limited operation range. Moreover, this topology needs an overrated inverter and high dc output voltage from DGs [8]. Multilevel converters have been increasingly used in the single-stage topology with better $\mathrm{dc}$ voltage utilization and output power quality.

In DGs with ac output power such as wind turbine or microturbine, the power electronic interfaces can be classified as double-stage or multi-stage converters as shown in Fig. 2. In the double-stage converters, the front-end PWM rectifier is usually used, and dc bus voltage is controlled by this rectifier. While in multi-stage topology, lower cost diode rectifier can be used, and dc-dc converter controls dc bus voltage. From cost point of view, the multi-stage topology could be more cost effective although it has low efficiency in comparison to two-stage topology [4].

With the development of power electronic technologies, multiple-port interfacing power converters are becoming more attractive in microgrid. Multiple-port power converters are used to connect various power sources (DGs or energy storage elements) to the grid and load through a single converter structure with lower cost and compact size [9-13]. The schematic diagram of this multiple-port interfacing converter is shown in Fig. 3.

These multi-port converters can be classified as electrically-coupled and magnetically-coupled structures. The electrically-coupled types are usually implemented with non-isolated topologies such as buck, boost, and buckboost switching cells $[9,10,12]$. In these topologies, in 


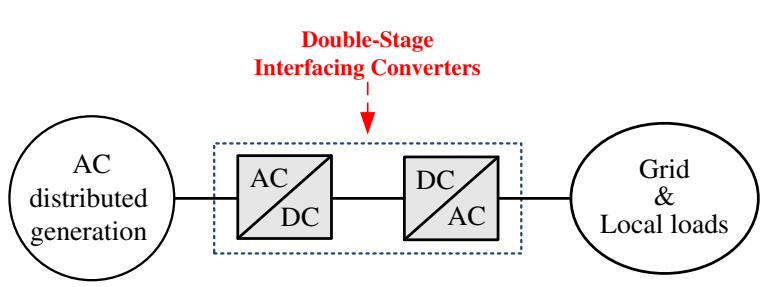

(a) double-stage ac-dc and dc-ac interfacing converters

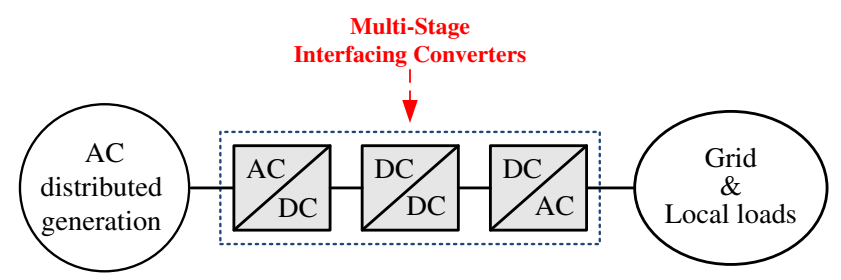

(b) multi-stage interfacing converters

Fig. 2 Power electronics interfaces for DGs with ac output powers

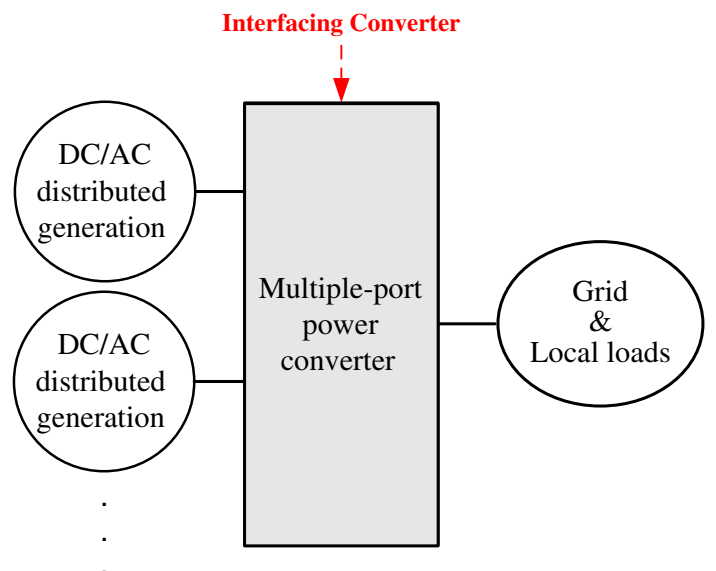

Fig. 3 Schematic diagram of multiple-port power electronic interfacing converter

order to avoid large buck/boost conversion ratios and to effectively handle the ports, the operating voltage of different power ports need to be close to each other. This constraint is the main drawback of electrically-coupled multiple-port converters [13]. In magnetically-coupled topologies, the energy sources are coupled through magnetic coupling (mainly high frequency ac-link), which provide electrical isolation between the power ports [9, 11]. In these topologies, because of the use of multi-winding transformers, DGs with different operating voltage levels can be connected to power ports. These converters can handle quite different operation levels of DGs and energy storage units, but with relatively complex structures and control systems.

Finally, different interfacing converter topologies such as Z-source converters [14], multi-level converters (neutral point clamp (NPC) [15, 16], cascaded H-bridge [17], multimodular converter [18, 19], etc.), soft-switching converters, matrix converters, etc., have been used in microgrids as DGs interfacing power electronics.

\section{Energy management schemes}

For sound operation of a microgrid in both grid-connected mode and stand-alone mode, proper energy management strategies are very important. These energy management schemes determine output powers and/or voltages of each DG source, which are then fed to the control system of interfacing converters as the control tracking references. Details of the converter control schemes will be explained in Section 4, while a review of the energy management schemes are provided here. In general, power management schemes in microgrids can be classified into communication-based and communicationless schemes.

\subsection{Communication-based energy management schemes}

In the communication-based energy management schemes, the system information (current, voltage, power, etc) is communicated in the microgrid to determine operation point of each DG. These schemes take the full advantage of intelligence in the integration of the computing and communications technologies in order to determine the output powers of each DG. Considering the distances of power sources, level of security, cost, and available technologies, appropriate communication method is determined. The communication methods can be based on fiber-optics, microwave, infrared, power line carrier (PLC), and/or wireless radio networks (GSM and CDMA) $[20,21]$. In these schemes, combination of Internet Protocol (IP) with existing industry protocols and standards are used to communicate over the grid.

In general, the communication-based energy management schemes can be divided into centralized and decentralized energy management schemes [22, 23]. These schemes are explained as follow.

\subsubsection{Centralized energy management scheme}

This strategy is also known as supervisory energy management. In general, master-slave control and central mode strategies belong to centralized energy management strategies. In this scheme, one centralized system or control center makes decisions and determines operation points of DGs. This control center receives all the measured signals of all energy units in microgrid, and sets the operating 


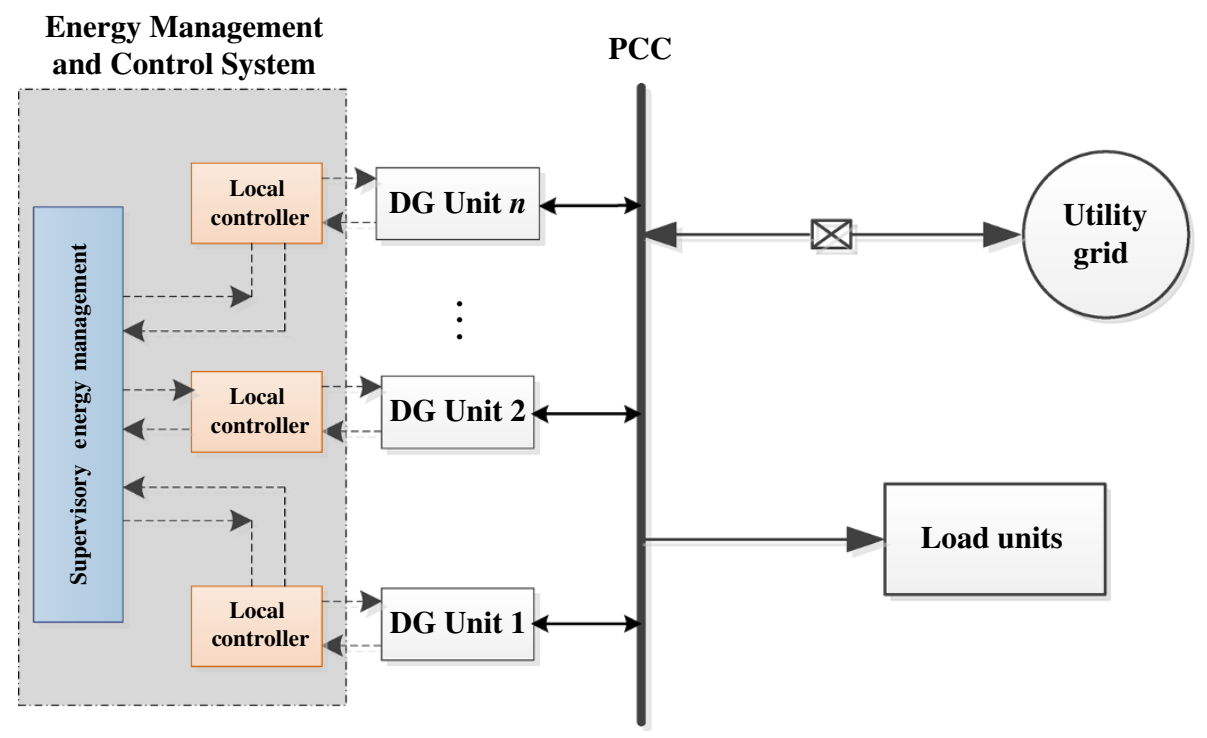

Fig. 4 Block diagram of centralized energy management scheme

points of DGs based on the objectives and constraints, which can be minimizing system operation and maintenance costs, environmental impact (carbon footprint), maximizing system efficiency, etc [22-25]. These objective functions along with the constraints can be conflicting and sometimes solving these problems is difficult (if not impossible). After making decisions, the control signals are sent to the DG local control systems. The DG local control is mainly realized by controlling the DG's power electronics converters. Figure 4 shows block diagram of centralized energy management scheme, where the DG units include both the energy sources and DG-grid interfacing power electronic converters.

An example of such supervisory energy management scheme is for microgrids based on PV-Wind-Battery-FC (fuel cell) input power sources [26]. In this work, the measured microgrid data are sent to the central system, and the objective function in the center controller is to provide the load power with high reliability.

The advantage of this centralized control scheme is that the central system receives all the data of system, and then based on the available information the multi-objective energy management system can achieve global optimization. However, heavy computation burden is one of its main drawbacks. Another drawback of this system is the reliability concern as a failure in the communication system may cause overall shut down in the system.

\subsubsection{Decentralized energy management scheme}

In decentralized energy management scheme, all the local controllers are connected through a communication bus. This bus is used to exchange data among DGs' controllers. In this energy management system, each local control system knows the operation point of other converters. This information is used to determine the DGs' operating points according to different optimization objectives [22, 23, 27]. In these systems, intelligent algorithm has been often used to find optimal operation point [28]. Figure 5 shows the block diagram of the decentralized energy management strategy.

This strategy has some advantages over centralized strategy. For example, it is easy to extend the control system to newly added energy sources with plug-and-play feature. Moreover, computation requirement of each controller is reduced, and the redundancy and modularity of the system is improved [22, 23]. However, failure in the communication link can still cause problem in the system (although unlike the supervisory control where a communication failure may collapse the system). Also, potential complexity of its communication system is still a concern of this strategy.

Multi-agent system (MAS) can be the best example of decentralized energy management system [23]. In MAS, autonomous computational agents make decisions based on goals within an environment, and they communicate information about their goal achievement to other independent agents [29-31]. These systems are mainly used for large and complex microgrids, and artificial-intelligencebased methods such as neural network or fuzzy systems are used to determine each DG's operation point while improving the overall performance of the microgrid [29-31].

In addition to centralized and decentralized energy management schemes, a combination of these schemes will produce a hybrid centralized and decentralized scheme. In 


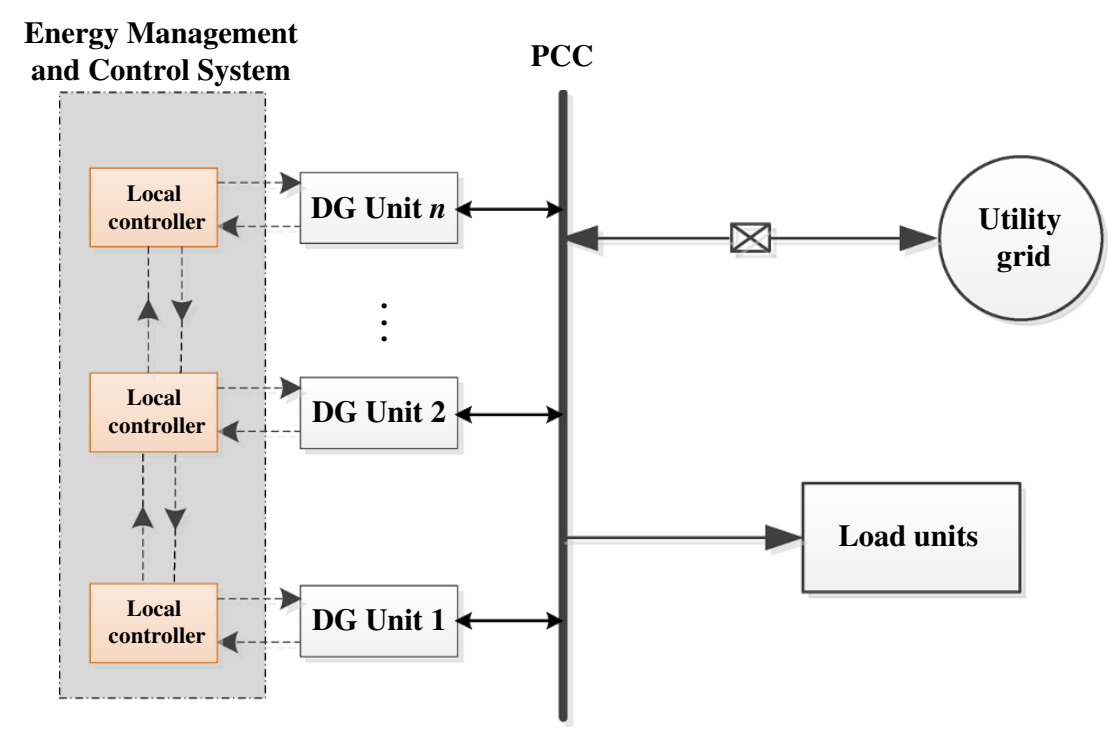

Fig. 5 Block diagram of decentralized energy management scheme

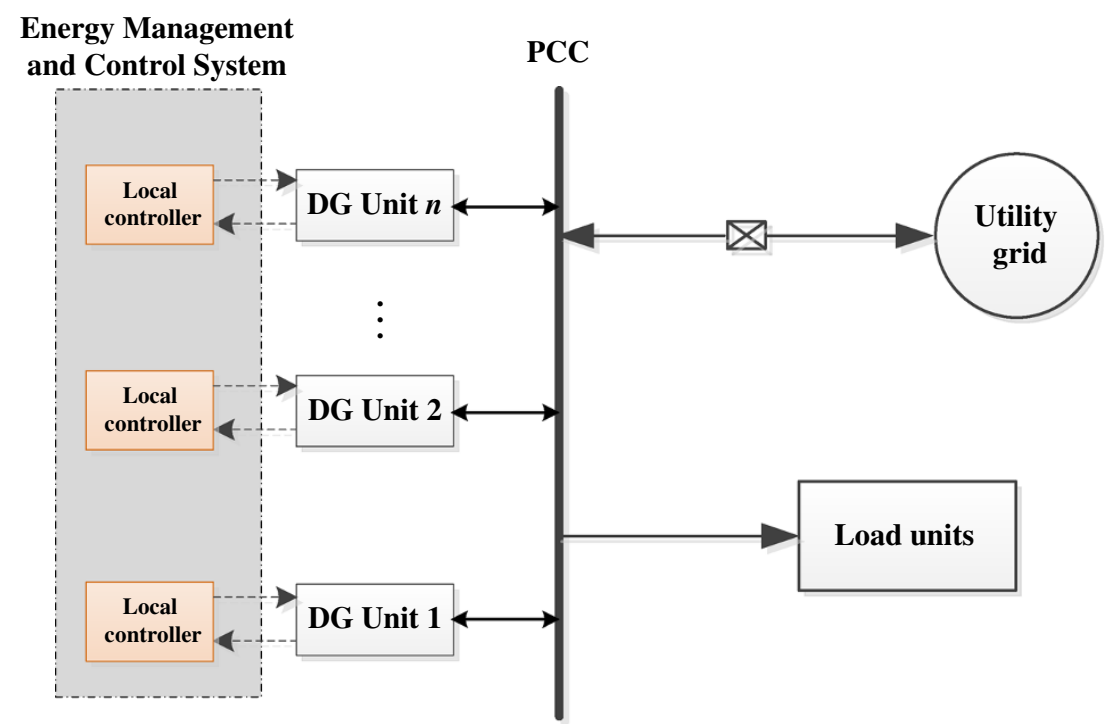

Fig. 6 Block diagram of communication-less energy management strategy

this hybrid strategy, DGs are divided into groups. In each group, centralized scheme is used, which is responsible for local optimization within group. Among different groups, decentralized energy management scheme is utilized for global optimization. Such a hybrid strategy could be suitable for large systems with interconnected microgrids, where centralize control of each microgrid and decentralized coordination among microgrids could improve reliability and resilience of the system. The recently proposed hierarchical energy management scheme can be considered as a hybrid centralized and decentralized energy management scheme [32-34].

\subsection{Communication-less energy management schemes}

The main idea of communication-less energy management strategy is that every DG unit must be able to operate independently when communication is too difficult or costly. Figure 6 shows the block diagram of communication-less energy management strategy. In these methods, each energy source has its own local controller without having communication links with the other controllers.

Droop control method is probably the most popular strategy in communication-less energy management $[5,35$, 36]. This method emulates the behavior of synchronous 
generator where the voltage and frequency vary with the DG output real and reactive power. The droop control is based on the assumption that the output impedance of DG is mainly inductive, and it uses droop characteristics of the voltage amplitude and frequency of the each DG to control its output [36]. In other words, the virtual communication link here is the microgrid voltage amplitude and frequency.

This strategy has obvious advantages: there is no communication requirement, so the control strategy is more reliable. Also, the control system is expandable with true plug-and-play function. However, there are some potential issues. First, in this method nonlinear loads are not considered and the nonlinear current sharing among DG units cannot be addressed directly. In addition, in low voltage microgrid systems, high $R / X$ line impedance ratio may lead to real and reactive power coupling and stability concerns $[37,38]$. Also, the mismatched DG output can cause power sharing error. Recent works have been done to improve droop control by adjusting the output voltage bandwidth, adding virtual impedance, or implementing the droop in virtual frames [37]. However, without a central control/ optimization algorithm, optimal operation of the microgrid system is still difficult with the communication-less based control strategy.

Other than the droop control method, if all DGs work at the MPPT mode, it is not necessity for communication between DGs. As a result, this method can also be considered as a communication-less energy management strategy. However, in such a system, energy storage devices are essential in stand-alone operation mode to provide the microgrid voltage and frequency regulation.

Considering the drawbacks of communication-based and communication-less energy management schemes, a combination of the droop control with communication-based control could have both improved reliability and control performance, and may be a good option for future microgrid systems. In such a combination strategy, with the help of communication-based energy management, the DG operation point in both grid-connected and stand-alone modes can be determined more accurately. Also with the droop control as backbone, the communication requirement (such as speed and bandwidth) can be reduced and failure of the communication links will not cause a system collapse.

\section{Interfacing converter control strategies}

The previously discussed energy management strategies determine operating point (such as power references) for each DG, and at the same time guarantee voltage and frequency regulations, load demand matching, etc. In the DG interfacing converter control system, the reference real and reactive powers are controlled through DG output current and voltage regulations. Therefore, the DGs output power control strategies are generally categorized as current control mode (CCM) and voltage control mode (VCM). These strategies are explained in following.

\subsection{CCM based power flow control strategy}

The CCM scheme is shown in Fig. 7. As seen from the figure, both active and reactive powers are tracked in the closed-loop manner. The real power control loop produces the synchronous frame $d$-axis reference current, while reactive power control loop generates the $q$-axis reference current. Note that the real power reference could be from energy management scheme or from a MPPT scheme. With these reference currents, the DG output current can then be controlled in the synchronous frame as shown in Fig. 7 or in the stationary $\alpha \beta$ frame. In this control strategy, the grid voltage angle information from phase-locked-loop (PLL) is used to synchronize the inverter output current with the grid voltage.

The $d$-axis reference current can also be generated by dc link voltage control. This condition occurs mainly in twostage converters (in either $\mathrm{dc}-\mathrm{dc}+\mathrm{dc}-\mathrm{ac}$ or $\mathrm{ac}-\mathrm{dc}+\mathrm{dc}-\mathrm{ac}$ ) where real power is controlled by first stage $(\mathrm{dc}-\mathrm{dc}$ or ac-dc converters). In other words, output real power of the inverter is controlled to regulate dc link voltage where the power difference between the input stage and inverter output can be used to charge or discharge the dc link capacitor [39, 40].

In general, the CCM based power flow control strategy is popularly used in grid-connected operation mode where the ac bus frequency and voltage are determined by the grid. However, in stand-alone operation of a microgrid, the CCM based method cannot directly regulate the microgrid voltage and frequency, and therefore the VCM based control strategy of at least one or more large DG units or energy storage units in a microgrid is necessary.

\subsection{VCM based power flow control strategy}

In this control strategy, output voltage of DG is controlled to regulate the DG output power, and the DG behaves like a synchronous generator. The droop control can be easily implemented on VCM based DG units.

Considering that the inverter is connected to ac bus through line impedance (Fig. 8) which is mainly inductive with high $X / R$ ratio, and the phase angle $\delta$ between inverter and ac bus is typically small, it can be concluded that the output active power of DG is proportional to the phase angle difference between inverter output voltage and grid voltage $(\delta)$, and the output reactive power is proportional to voltage magnitude difference $\left(V_{1}-V_{g}\right)$. Therefore, the output active power can be controlled by the DG output 


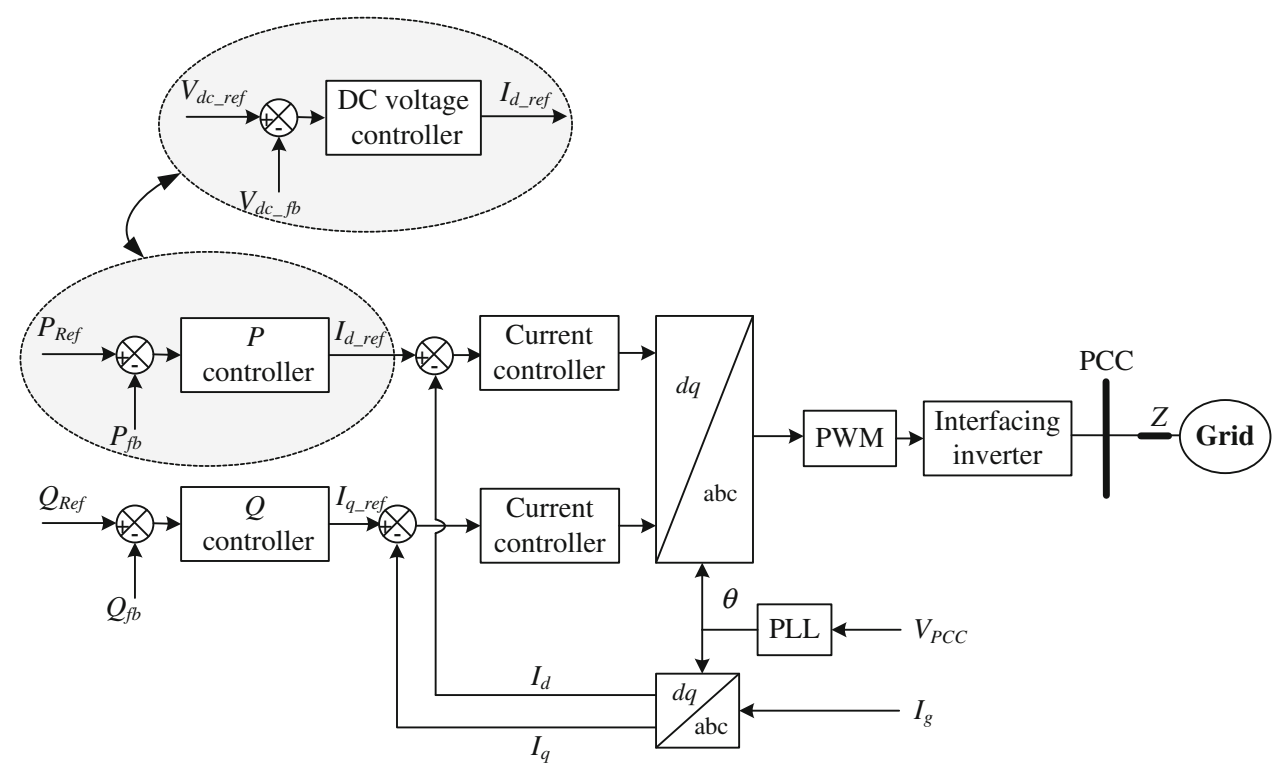

Fig. 7 Current-based real and reactive power control strategy

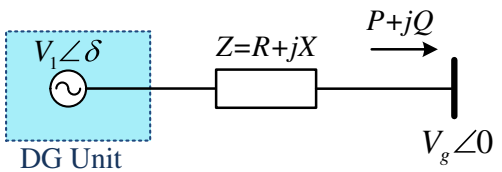

Fig. 8 Equivalent circuit of DG unit connected to the common ac bus

phase angle (or frequency), and the output reactive power can be controlled by the DG output voltage magnitude.

The block diagram of this control strategy is shown in Fig. 9. This control scheme can be applied for both gridconnected and stand-alone operation modes of microgrids $[5,6,41]$. In this figure, the active and reactive power references are provided by power management strategies. As discussed, in this strategy, the output voltage phase angle is determined by active power controller and the output voltage magnitude is controlled by the reactive power controller. The DG output three-phase voltages are regulated on their reference values with closed-loop control system. In this strategy, the voltage closed-loop control system can have an inner current loop for transient and stability performance improvement [42]. In this control scheme, the active and reactive power controllers can be proportional controllers for realizing active power-frequency droop $(P-\omega)$ and reactive power-voltage magnitude droop $(Q-V)$. More complex controller can also be used here to closely mimic the synchronous generator with excitation and torque dynamics [43].

Compared to CCM based control, the main advantage of VCM based control is that it can be used in both grid-connected and stand-alone operation modes, which makes the operation mode transition easy and smooth. Possible issues when utilizing this method are mainly related to the lack of direct control of DG output current, especially during fault or grid voltage disturbances. These problems can be avoided by implementing virtual impedance control at the DG output $[38,44]$.

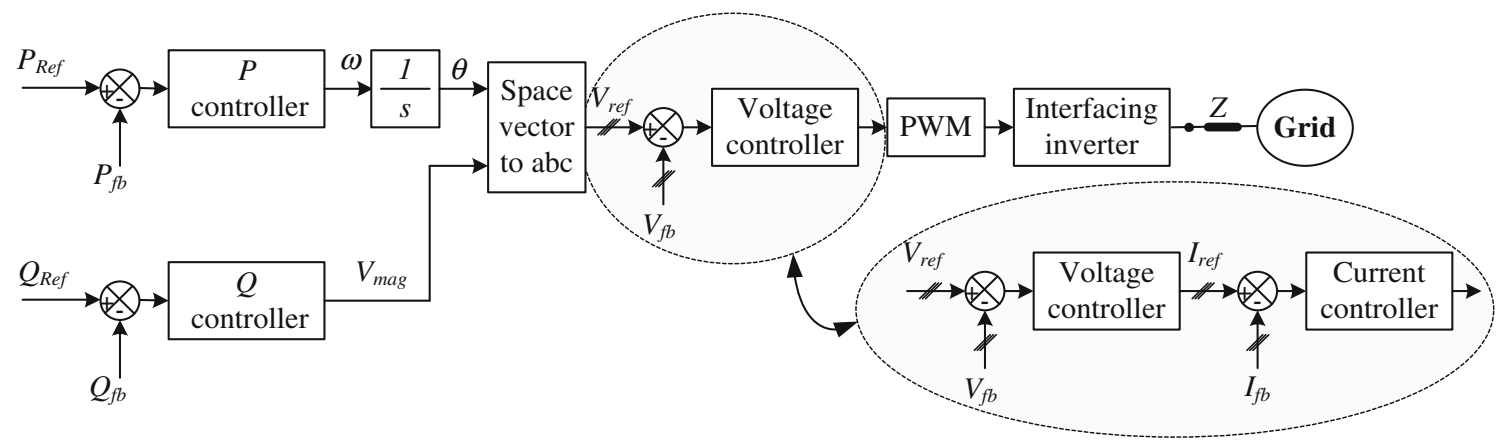

Fig. 9 Voltage-based real and reactive power control strategy 


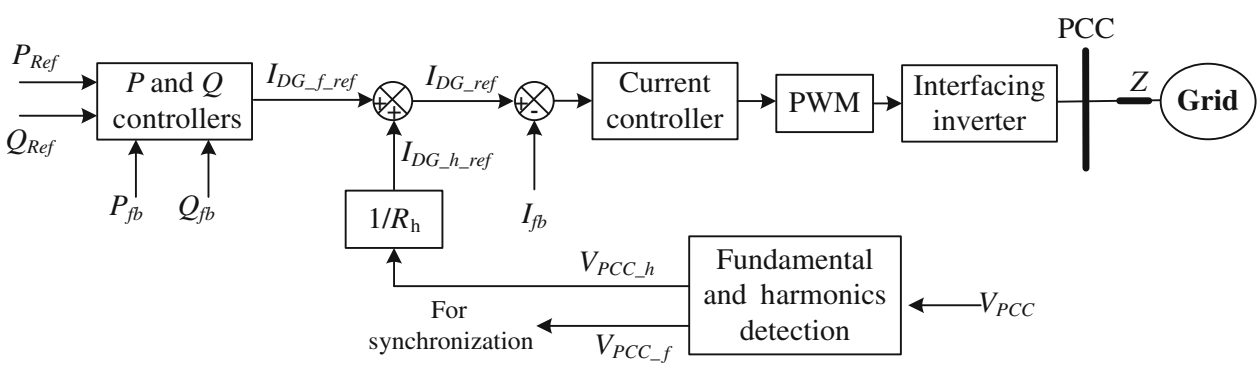

Fig. 10 CCM based DG control for harmonic compensation

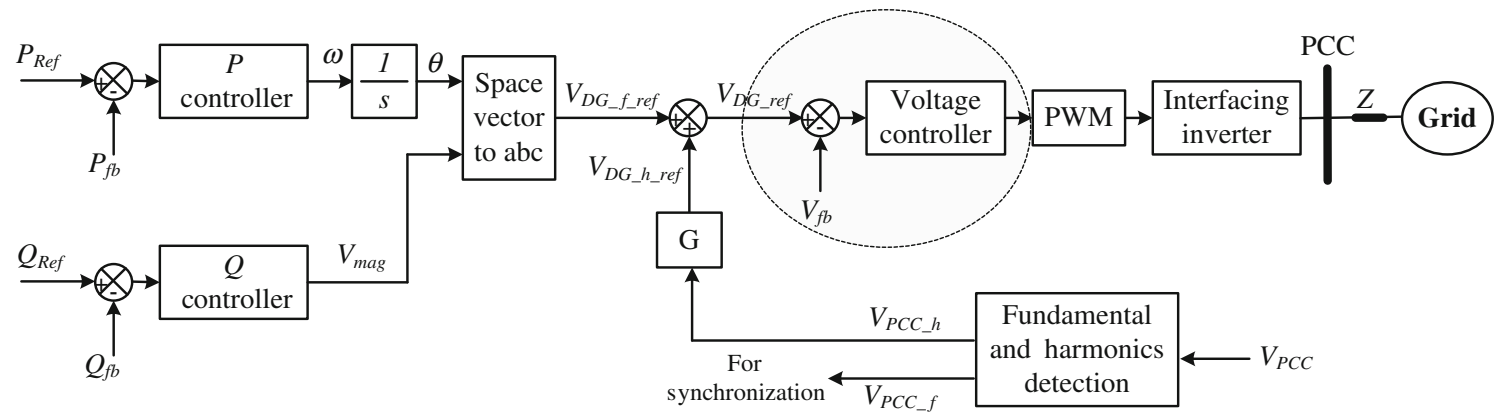

Fig. 11 VCM based DG control for harmonic compensation

\section{Ancillary services}

Ancillary services for DG systems are becoming an important issue that may further improve the cost effectiveness of DG systems. This is a promising idea especially considering that many renewable energy based DG systems (such as PV and wind) do not operate at the maximum rating all the time (PV systems simply idles during the night). As a result, the available ratings from these DGs' interfacing converters can be utilized to provide ancillary services such as flicker mitigation [45], unbalance voltage compensation [46, 47], harmonic control [48], power factor correction etc. Here the harmonics compensation and unbalance voltage compensation are briefly discussed.

\subsection{Harmonics compensation}

The power electronics interfaced DGs can be controlled like active power filters at the harmonic frequencies to mitigate system harmonics. As mentioned in Section 4, there are two types of control strategies in DG systems: CCM and VCM. The CCM based control strategy is widely adopted in active power filters to mitigate harmonics [49]. As a result, CCM based DGs can be easily controlled as shunt active power filters to absorb harmonic currents produced by nonlinear loads. To do this, DGs can be controlled to act as virtual resistances at the selected harmonic frequencies. The block diagram of CCM based DG control method for harmonic compensation is shown in Fig. 10. In this control method, the reference active and reactive power control loops produce DG's output fundamental reference current $I_{D G_{-} f_{-} r e f}$ (similar to Fig. 7). The reference harmonics current of DG is produced by harmonic component of PCC voltage divided by the desired virtual resistance value $\left(I_{h_{-} \text {ref }}=V_{P C C_{-} h} / R_{h}\right)$. By behaving as a small virtual resistor at the harmonic frequencies, the DG will help to absorb the nonlinear load current and improve the system power quality.

In VCM based DG systems, the current-controlled harmonic compensation schemes mentioned before are not applicable, as they cannot directly control the DG output current. The VCM based control strategy of DGs for harmonic compensation is shown in Fig. 11. In this control scheme, the fundamental reference voltage of DG is produced by active and reactive power control (similar to the control scheme in Fig. 9), while the harmonic reference voltage of DG is produced by measuring the harmonic components of PCC voltage with $V_{D G \_h \_r e f}=V_{P C C \_h} G$ [48]. As a result, the DG will behave as an impedance of $Z_{D G \_e q}=Z_{D G} /(1+G)$, where $Z_{D G}$ is the impedance of DG side [48]. Obviously, by scaling down the DG side impedance, the harmonics will be absorbed by the DG unit. Finally, the more recently proposed hybrid voltage and current control scheme can regulate the fundamental voltage and harmonic current at the same time, and therefore is expect to be more flexible in term of providing the harmonics regulation services [50]. 


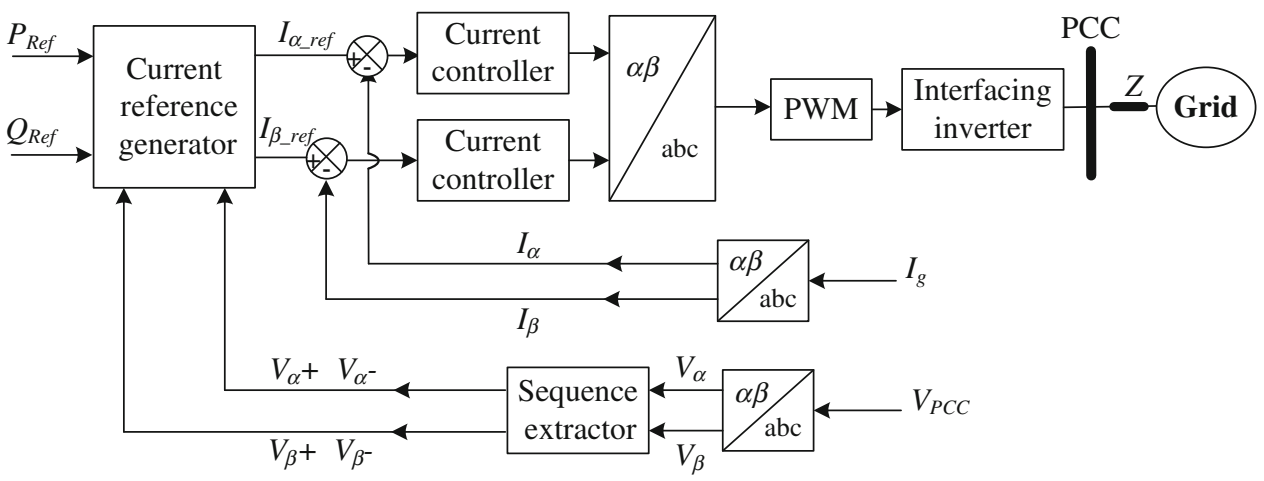

Fig. 12 Control diagram of power electronic-interfaced DG for unbalance voltage compensation

\subsection{Unbalance voltage compensation}

Using the DG interfacing converters to compensate the grid voltage unbalance can be an important ancillary service for the utility, where the unbalanced loads could cause serious unbalanced voltage resulting in poor power quality and even protection responses. For unbalance compensation, DG mitigates/reduces voltage sag and unbalances by injecting additional negative sequence current. Therefore, the DG injected current contains both positive sequence and negative sequence components where the positive sequence component can help to improve the power factor or voltage support as discussed earlier, while the negative sequence component could reduce negative sequence of voltage at PCC [46].

The control block diagram of DG for unbalance voltage compensation is shown in Fig. 12. Here, different sequence extractor can be used to extract positive and negative sequence component of the voltage [51-53]. Moreover, the active power reference is provided by power management strategies or dc-link voltage regulator, and reactive power reference is provided by voltage support strategies, phase current limitation scheme, etc [46]. Based on the reference active and reactive powers, and positive and negative sequences of PCC voltage, reference currents of DG (in $\alpha \beta$ frame) are produced as following [54]:

$$
\begin{aligned}
I_{\alpha \_r e f}= & P_{R e f}\left(\frac{k_{1}}{\left|v^{+}\right|^{2}} V_{\alpha}^{+}+\frac{\left(1-k_{1}\right)}{\left|v^{-}\right|^{2}} V_{\alpha}^{-}\right) \\
& +Q_{\text {Ref }}\left(\frac{k_{2}}{\left|v^{+}\right|^{2}} V_{\beta}^{+}+\frac{\left(1-k_{2}\right)}{\left|v^{-}\right|^{2}} V_{\beta}^{-}\right) \\
I_{\beta \_r e f}= & P_{\operatorname{Ref}}\left(\frac{k_{1}}{\left|v^{+}\right|^{2}} V_{\beta}^{+}+\frac{\left(1-k_{1}\right)}{\left|v^{-}\right|^{2}} V_{\beta}^{-}\right) \\
& -Q_{\operatorname{Ref}}\left(\frac{k_{2}}{\left|v^{+}\right|^{2}} V_{\alpha}^{+}+\frac{\left(1-k_{2}\right)}{\left|v^{-}\right|^{2}} V_{\alpha}^{-}\right)
\end{aligned}
$$

where $P_{\text {Ref }}$ and $Q_{\text {Ref }}$ are DG reference active and reactive powers; $V_{\alpha}^{+}, V_{\alpha}^{-}, V_{\beta}^{+}$and $V_{\beta}^{-}$are the positive and negative sequences of PCC voltage; $\left|v^{+}\right|$and $\left|v^{-}\right|$are the amplitude of positive and negative sequences of PCC voltage; $k_{1}$ and $k_{2}$ are the control gains which provide flexible control of positive and negative sequences of active and reactive powers. By controlling these gains, different control strategies such as active power oscillation cancellation, reactive power oscillation cancellation, etc. can be obtained as mentioned before [54]. Similarly, other objectives such as dc link ripple minimization, DG phase current limitation, etc. can also be considered in this control system by properly designing the gains of $k_{1}$ and $k_{2}$.

Finally, other than the above mentioned ancillary services, the DG systems or microgrid as a whole can be used to improve the power system operation by providing the reserve functions [55]. For these reserve functions, the DG or microgrid can be controlled with frequency or voltage droop control and help to the grid frequency and voltage regulations. This can be done by the DG systems alone or collectively with both the DG and load response control. With more controllability and flexibility in a microgrid system, valuable ancillary functions can be provided for better grid operation and better grid power quality.

\section{Conclusion}

Microgrid is becoming an important aspect of future smart grid, which features great control flexibility, improved reliability, and better power quality. The important aspects of the microgrid are the grid integration and energy management strategies, which enables sound operation of the microgrid in both grid-connected mode and stand-alone mode. This paper conducts an overview of grid integration technologies and energy management strategies of microgrids. It shows that the recent research trend on the DG interfacing converter is focused on better efficiency, reduced size, multi-port and modular design. 
For the energy management strategy, a hybrid combination of communication-based and communication-less energy management technologies could be a good balance of system optimal operation, reliability, and resilience. In this paper, the interfacing converter control schemes are also discussed, and it shows that VCM based methods are gaining more attention due to its ability to mimic the behavior of a synchronous generator. At last, this paper discusses the ancillary services of DGs. The ancillary service is becoming a promising topic to further assist the grid control, enhance the grid power quality and, at the same time, to improve the cost effectiveness of power electronic based DGs and microgrids.

Open Access This article is distributed under the terms of the Creative Commons Attribution License which permits any use, distribution, and reproduction in any medium, provided the original author(s) and the source are credited.

\section{References}

[1] Global wind report: Annual market update 2011 (2012) Global Wind Energy Council (GWEC), Brussels

[2] Global market outlook for photovoltaic until 2016 (2012) European Photovoltaic Industry Association (EPIA), Brussels

[3] Kramer W, Chakraborty S, Kroposki B et al (2008) Advanced power electronic interfaces for distributed energy systems, Part 1: Systems and topologies. NREL/TP-581-42672, National Renewable Energy Laboratory (NREL), Golden

[4] Carrasco JM, Franquelo LG, Bialasiewicz JT et al (2006) Powerelectronic systems for the grid integration of renewable energy sources: a survey. IEEE Trans Ind Electron 53(4):1002-1016

[5] Li YW, Vilathgamuwa DM, Loh PC (2004) Design, analysis and real-time testing of controllers for multibus microgrid system. IEEE Trans Power Electron 19(5):1195-1204

[6] Katiraei F, Iravani MR (2006) Power management strategies for a microgrid with multiple distributed generation units. IEEE Trans Power Syst 21(4):1821-1831

[7] Hatziargyriou N, Asano H, Iravani R et al (2007) Microgrids. IEEE Power Energ Mag 5(4):78-94

[8] Xue Y, Chang L, Kjaer SB et al (2004) Topologies of singlephase inverters for small distributed power generators: an overview. IEEE Trans Power Electron 19(5):1305-1314

[9] Jiang W, Fahimi B (2011) Multiport power electronic interface-Concept, modeling, and design. IEEE Trans Power Electron 26(7):1890-1900

[10] Chen YM, Liu YC, Hung SC et al (2007) Multi-input inverter for grid-connected hybrid PV/wind power system. IEEE Trans Power Electron 22(3):1070-1077

[11] Sarhangzadeh M, Hosseini SH, Sharifian MBB et al (2011) Multiinput direct DC-AC converter with high-frequency link for clean power-generation systems. IEEE Trans Power Electron 26(6):1777-1789

[12] Nejabatkhah F, Danyali S, Hosseini SH et al (2012) Modeling and control of a new three-input DC-DC boost converter for hybrid PV/FC/battery power system. IEEE Trans Power Electron 27(5):2309-2324

[13] Tao H, Duarte JL, Hendrix MAM(2008) Multiport converters for hybrid power sources. In: Proceedings of the IEEE power electronics specialists conference (PESC'08), Rhodes, 15-19, pp 3412-3418
[14] Peng FZ (2003) Z-source inverter. IEEE Trans Ind Appl 39(2):504-510

[15] Alepuz S, Busquets-Monge S, Bordonau J et al (2006) Interfacing renewable energy sources to the utility grid using a threelevel inverter. IEEE Trans Ind Electron 53(5):1504-1511

[16] Yazdani A, Iravani R (2006) A neutral-point clamped converter system for direct-drive variable-speed wind power unit. IEEE Trans Energ Conver 21(2):596-609

[17] Villanueva E, Correa P, Rodriguez J et al (2009) Control of a single-phase cascaded H-bridge multilevel inverter for gridconnected photovoltaic systems. IEEE Trans Ind Electron 56(11):4399-4406

[18] Akagi H (2011) Classification, terminology, and application of the modular multilevel cascaded converter (MMCC). IEEE Trans Power Electron 26(11):3119-3130

[19] Islam MR, Guo Y, Zhu J (2014) A high-frequency link multilevel cascaded medium-voltage converter for direct grid integration of renewable energy systems. IEEE Trans Power Electron 29(8):4167-4182

[20] Islam SZ, Mariun N, Hizam H et al (2012) Communication for distributed renewable generations (DRGs): A review on the penetration to smart grids (SGs). In: Proceedings of the 2012 IEEE international conference on power and energy (PECON'12), Kota Kinabalu, 2-5: pp 870-875

[21] Bouhafs F, Mackay M, Merabti M (2012) Links to the future: Communication requirements and challenges in the smart grid. IEEE Power Energ Mag 10(1):24-32

[22] Nehrir MH, Wang C, Strunz K et al (2011) A review of hybrid renewable/alternative energy systems for electric power generation: configurations, control, and applications. IEEE Trans Sustain Energ 2(4):392-403

[23] Katiraei F, Iravani R, Hatziargyriou N et al (2008) Microgrids management. IEEE Power Energ Mag 6(3):54-65

[24] Colet-Subirachs A, Ruiz-Alvarez A, Gomis-Bellmunt $O$ et al (2012) Centralized and distributed active and reactive power control of a utility connected microgrid using IEC61850. IEEE Syst J 6(1):58-67

[25] Tan KT, Peng XY, So PL et al (2012) Centralized control for parallel operation of distributed generation inverters in microgrids. IEEE Trans Smart Grid 3(4):1977-1987

[26] Wang C, Nehrir MH (2008) Power management of a stand-alone wind/photovoltaic/fuel-cell energy system. IEEE Trans Energ Conver 23(3):957-967

[27] Cheng YJ, Sng EKK (2006) A novel communication strategy for decentralized control of paralleled multi-inverter systems. IEEE Trans Power Electron 21(1):148-156

[28] Colson CM, Nehrir MH (2013) Comprehensive real-time microgrid power management and control with distributed agents. IEEE Trans Smart Grid 4(1):617-627

[29] Ren F, Zhang M, Sutanto D (2013) A multi-agent solution to distribution system management by considering distributed generators. IEEE Trans Power Syst 28(2):1442-1451

[30] Zhao P, Suryanarayanan S, Simoes MG (2013) An energy management system for building structures using a multi-agent decision-making control methodology. IEEE Trans Ind Appl 49(1):322-330

[31] Ko HS, Jatskevich J (2007) Power quality control of windhybrid power generation system using fuzzy-LQR controller. IEEE Trans Energ Conver 22(2):516-527

[32] Guerrero JM, Vasquez JC, Matas J et al (2011) Hierarchical control of droop-controlled AC and DC microgrids-A general approach toward standardization. IEEE Trans Ind Electron 58(1):158-172

[33] Dou CX, Duan ZS, Liu B (2013) Two-level hierarchical hybrid control for smart power system. IEEE Trans Automat Sci Eng 10(4):1037-1049 
[34] Jiang Z, Dougal RA (2008) Hierarchical microgrid paradigm for integration of distributed energy resources. In: Proceedings of the Power and Energy Society general meeting-Conversion and delivery of electrical energy in the 21 st century (PES'08), Pittsburgh, 20-24: 8 pp

35. Chandorkar MC, Divan DM, Adapa R (1993) Control of parallel connected inverters in standalone AC supply systems. IEEE Trans Ind Appl 29(1-1):136-143

[36] Guerrero JM, De Vicuña G, Matas J et al (2004) A wireless controller to enhance dynamic performance of parallel inverters in distributed generation systems. IEEE Trans Power Electron 19(5):1205-1213

[37] Li Y, Li YW (2011) Power management of inverter interfaced autonomous microgrid based on virtual frequency-voltage frame. IEEE Trans Energ Conver 2(1):30-40

[38] Li YW, Kao CN (2009) An accurate power control strategy for power-electronics-interfaced distributed generation units operating in a low-voltage multibus microgrid. IEEE Trans Power Electron 24(12):2977-2988

[39] Blaabjerg F, Teodorescu R, Liserre M et al (2006) Overview of control and grid synchronization for distributed power generation systems. IEEE Trans Ind Electron 53(5):1398-1409

[40] Yazdani A, Iravani R (2010) Voltage-sourced converter in power systems: modelling, control, and application. Wiely, New York

[41] Pogaku N, Prodanovic M, Green TC (2007) Modeling, analysis and testing of autonomous operation of an inverter-based microgrid. IEEE Trans Power Electron 22(2):613-625

[42] Li YW (2009) Control and resonance damping of voltage-source and current-source converters with LC filters. IEEE Trans Ind Electron 56(5):1511-1521

[43] Zhong QC, Weiss G (2011) Synchronverters: inverters that mimic synchronous generators. IEEE Trans Ind Electron 58(4):1259-1267

[44] He J, Li YW (2011) Analysis, design and implementation of virtual impedance for power electronics interfaced distributed generation. IEEE Trans Ind Appl 47(6):2525-2538

[45] Marei MI, Abdel-Galil TK, El-Saadany EF et al (2005) Hilbert transform based control algorithm of the DG interface for voltage flicker mitigation. IEEE Trans Power Deliver 20(2-1):1129-1133

[46] Camacho A, Castilla M, Miret J et al (2013) Flexible voltage support control for three-phase distributed generation inverters under grid fault. IEEE Trans Ind Electron 60(4):1429-1441

[47] Li YW, Vilathgamuwa DM, Loh PC (2005) Microgrid power quality enhancement using a three-phase four-wire grid-interfacing compensator. IEEE Trans Ind Appl 41(6):1707-1719

[48] He J, Li YW, Munir MS (2012) A flexible harmonic control approach through voltage-controlled DG-grid interfacing converters. IEEE Trans Ind Electron 59(1):444-456
[49] Lee TL, Cheng PT, Akagi $\mathrm{H}$ et al (2008) A dynamic tuning method for distributed active filter systems. IEEE Trans Ind Appl 44(2):612-623

[50] He J, Li YW (2013) Hybrid voltage and current control approach for DG-grid interfacing converters with LCL filters. IEEE Trans Ind Electron 60(5):1797-1809

[51] Rodriguez P, Pou J, Bergas J et al (2007) Decoupled double synchronous reference frame PLL for power converters controls. IEEE Trans Power Electron 22(2):584-592

[52] Rodriguez P, Luna A, Candela I et al (2011) Multiresonant frequency-locked loop for grid synchronization of power converters under distorted grid conditions. IEEE Trans Ind Electron 58(1):127-138

[53] Wang YF, Li YW (2011) Grid synchronization PLL based on cascaded delayed signal cancellation. IEEE Trans Power Electron 26(7):1987-1997

[54] Teodorescu R, Liserre M, Rodriguez P (2011) Grid converters for photovoltaic and wind power systems. Wiley, New York

[55] Vandoorn TL, Vasquez JC, De Kooning J et al (2013) Microgrids: Hierarchical control and an overview of the control and reserve management strategies. IEEE Ind Electron Mag $7(4): 42-45$

Yunwei LI (S'04-M'05-SM'11), Senior Member, IEEE, received the B.Eng. in electrical engineering from Tianjin University, Tianjin, China, in 2002, and the Ph.D. degree from Nanyang Technological University, Singapore, in 2006. In 2005, Dr. Li was a Visiting Scholar with Aalborg University, Denmark. From 2006 to 2007, he was a Postdoctoral Research Fellow at Ryerson University, Canada. In 2007, he worked at Rockwell Automation Canada and later joined the Department of Electrical and Computer Engineering, University of Alberta, Canada in the same year. Dr. Li is currently an Associate Professor at University of Alberta. His research interests include distributed generation, microgrid, renewable energy, high power converters and electric motor drives. He serves as an Associate Editor for IEEE Transactions on Power Electronics and IEEE Transactions on Industrial Electronics. He also worked as a Guest Editor for the IEEE Transactions on Industrial Electronics Special Session on Distributed Generation and Microgrids. Dr. Li received the 2013 Richard M. Bass Outstanding Young Power Electronics Engineer Award from IEEE Power Electronics Society.

Farzam NEJABATKHAH (S'09) Received the B.Sc. and M.Sc. degrees (both with first-class honors) in electrical engineering from University of Tabriz, Iran, in 2009 and 2011, respectively. He is currently pursuing $\mathrm{Ph} . \mathrm{D}$. degree in University of Alberta, Canada, where he has been awarded Alberta Innovates Scholarship. His research interests include distributed generation, power converters, and energy management of hybrid microgrids. 